\title{
Diretrizes para planejar e controlar o processo de montagem de sistemas construtivos pré- fabricados de aço
}

\author{
Guidelines for planning and controlling the assembly \\ process of prefabricated steel building systems
}

\section{Fabiana Fabro \\ lamara Rossi Bulhões \\ Carlos Torres Formoso \\ Marcus Costa Tenório Fireman}

\section{Resumo}

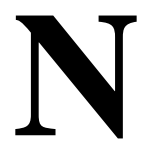

os últimos anos, tem se observado um aumento na utilização de sistemas construtivos industrializados, entre os quais estruturas metálicas, que podem contribuir para eliminar perdas e reduzir duração dos empreendimentos. O presente trabalho tem como objetivo propor um conjunto de diretrizes para o planejamento e controle do processo de montagem de estruturas metálicas préfabricadas, utilizando conceitos e ferramentas relacionados à Produção Enxuta. A abordagem metodológica utilizada foi design science research, sendo o trabalho desenvolvido em parceria com uma empresa que projeta, fábrica e monta sistemas construtivos em aço. Foram implementadas diversas melhorias no planejamneto e controle da produção (PCP) da empresa, em duas etapas: a primeira com a participação de um pesquisador como facilitador do processo; e a segunda com a implementação conduzida por gerentes da própria empresa. Os resultados obtidos evidenciaram a necessidade de adaptação dos modelos de PSP e do PCP existentes na literatura ao contexto de sistemas de estruturas metálicas. A principal contribuição do trabalho foi a proposição de um conjunto de diretrizes para conceber o processo de PCP em empresas que fornecem sistemas construtivos de aço.

Palavras-chave: Sistema Last Planner. Projeto do sistema de produção. Sistemas construtivos de aço. Produção Enxuta.

${ }^{1}$ Fabiana Fabro

${ }^{1}$ Universidade Federal do Rio Grande

do Sul

Porto Alegre - RS - Brasil

${ }^{2}$ lamara Rossi Bulhões

2 Universidade Federal do Rio Grande

do Sul

Tramandaí - RS - Brasil

${ }^{3}$ Carlos Torres Formoso ${ }^{3}$ Universidade Federal do Rio Grande

Porto Alegre - RS - Brasil

${ }^{4}$ Marcus Costa Tenório Fireman

4Universidade Federal do Rio Grande do Sul

Porto Alegre - RS - Brasil

Recebido em 30/03/19

Aceito em 21/09/19

\section{Abstract}

In recent years, the construction industry has been increasingly using industrialised construction systems, including steel structures, which can contribute to waste elimination and reduction in project duration. The aim of this research study is to propose a set of guidelines for planning and controlling the assembly process of prefabricated steel structures, based on Lean Production concepts and principles. Design science research was the methodological approach adopted in this investigation, which was developed in partnership with a company that designs, produces and assembles steel building systems. Several improvements were implemented in the planning and control process of the company, in two stages: the first one had the participation of one researcher as a facilitator, and the second one was led by company's managers. Results indicate that there is a need to adapt modelsproposed in the literature for production system design and production planning and control to the context of prefabricated steel building systems. The main contributionof this investigation is a set of guidelines that can be used to conceive the production planning and control process for companies that design, produce and assemble prefabricated steel structures.

Keywords: Last Planner System. Production system design. Line of Balance. Steel building systems. Lean Production.

FABRO, F.; BULHÕES, I. R.; FORMOSO, C. T. Marcus Costa Tenório Fireman Diretrizes para planejar e controlar o processo de montagem de sistemas construtivos pré-fabricados de aço. Ambiente Construído, Porto Alegre, v. 20 , n. 2, p. 505-524, abr./jun. 2020.

ISSN 1678-8621 Associação Nacional de Tecnologia do Ambiente Construído.

http:/ / dx. doi. org/ 10.1590/ s1678-86212020000200412 


\section{Introdução}

Diversos estudos (TOMMELEIN, 1998, AKEL et al., 2001; BALLARD; HARPER; ZABELLE, 2003; SACKS; AKINCI; ERGEN, 2003; BULHÕES; PICCHI, 2013; VIANA; TOMMELEIN; FORMOSO, 2017; BORTOLINI; FORMOSO; VIANA, 2019; BATAGLIN et al., 2019) foram realizados com a finalidade de compreender e propor melhorias nos sistemas de gestão de empresas de produtos pré-fabricados para a construção, utilizando conceitos e princípios da filosofia da Produção Enxuta. Segundo Sacks, Akinci e Ergen (2003), uma das principais dificuldades na gestão de sistemas produtivos pré-fabricados é a necessidade de puxar a produção de acordo com a demanda do cliente. Os referidos autores apontam que os fornecedores destes sistemas normalmente produzem as peças com bastante antecedência em relação à montagem em obra, resultando em níveis de estoques relativamente grandes, acumulados em pátios das fábricas ou nas obras. Um outro fator que contribui para a formação de tais estoques de materiais é a falta de comunicação, em tempo hábil, entre o canteiro de obras e a fábrica, a fim de transmitir informações sobre o real andamento da execução física do empreendimento, para que, com base nessas informações, a produção dos setores a montante possa ser puxada (SACKS; AKINCI; ERGEN, 2003).

Além disto, o processo produtivo na construção civil tem um elevado nível de incerteza. Howell, Laufer e Ballard (1993) classificam tais incertezas em duas categorias:

(a) aquelas que são provenientes de fatores externos à construção, como, por exemplo, variações da demanda de mercado, mudanças climáticas, alterações por parte dos clientes nos projetos e nos prazos da obra, atrasos de fornecedores e dificuldade em subcontratar empresas para a execução da obra; e

(b) aquelas que são provenientes de fatores internos da empresa, tais como a variabilidade na duração das atividades e $\mathrm{o}$ alto grau de interdependência entre as atividades.

Uma das estratégias adotadas para minimizar os impactos negativos das incertezas é mobilizar recursos em quantidades suficientes, para permitir que o trabalho tenha continuidade, independentemente das sequências de entrega de materiais e da sequência de execução (HOWELL; BALLARD, 1996). Esta estratégia, apesar de aumentar a taxa de utilização da capacidade dos recursos, tais como mão de obra e equipamentos, não garante que se produza o que é necessário, quando necessário, conforme o princípio de puxar a produção, adotado na filosofia da Produção Enxuta (HOWELL; BALLARD, 1996).

Ainda, a necessidade de utilização destes estoques de materiais entre os processos causa desbalanceamento entre as taxas da oferta de recursos (ritmo de fabricação) e as de consumo (ritmo de montagem) (BERNHOLD, 1989; KOSKELA, 1992). Para os referidos autores, estas taxas são difíceis de combinar, pois ambas são instáveis. Assim, um esforço continuado e integrado de planejamento e controle da produção (PCP) é necessário para ajustar todos os processos da empresa de acordo com o ritmo da montagem das obras (LEMNA et al., 1986; LAUFER et al., 1994).

Os sistemas pré-fabricados de aço normalmente são classificados como engineer-to-order (ETO) (VIANA, 2015; BORTOLINI; FORMOSO; VIANA, 2019). Este tipo de sistema de produção tem como principal característica o fato de que o pedido por parte dos clientes desencadeia o início do empreendimento e, posteriormente, da produção. Nos sistemas ETO existe um elevado nível de incerteza quanto ao produto a ser fabricado conforme a encomenda por parte do cliente, uma vez que não se conhece os componentes a serem utilizados ou a sequência de fabricação dos mesmos (BERTRAND;e MUNTSLAGL, 1993). Em ambientes ETO, existe um elevado grau de incerteza e complexidade, sendo necessário enfatizar o uso de sistemas de planejamento e controle que possibilitem a integração das diferentes fases do empreendimento: projeto, fabricação e montagem (LITTLE et al., 2000).

Segundo Howell e Ballard (1996), o sucesso no desenvolvimento de um empreendimento por parte de empresas que produzem produtos pré-fabricados é alcançado com a gestão das incertezas durante a execução dos processos de fabricação e montagem dos produtos em canteiro. O Sistema Last Planner de Controle da Produção (SLP) é apontado como uma forma de estruturar o PCP, visando a melhorar a gestão das obras em ambientes de elevada incerteza, sendo este modelo de planejamento e controle fundamentado na filosofia da Produção Enxuta (BALLARD; HOWELL, 1998).

Entretanto, no setor da construção civil é comum a execução do empreendimento sem que seja realizado um efetivo processo de PCP, incluindo a coordenação de recursos, controle de capacidades produtivas, liberação de ordens de serviço e controle das unidades de produção, tarefas comuns ao ambiente fabril (BERTRAND et 
al., $1990^{1}$ apud BALLARD; HOWELL, 1998). Em que pese a realização de muitos estudos sobre o SLP, há poucos estudos na literatura relativos a sistemas de PCP que integrem a elaboração de projetos, a fabricação das peças e a montagem destes elementos no canteiro de obras (TOMMELEIN; WEISSENBERGER,1999; BULHÕES, 2009).

O presente trabalho tem como objetivo propor um conjunto de diretrizes para o planejamento e controle do processo de montagem de obras em estrutura metálicas, utilizando conceitos e ferramentas relacionados à Produção Enxuta. Explora-se neste trabalho a implementação de dois modelos de planejamento e controle, o Projeto do Sistema de Produção (PSP), tal qual definido por Schramm, Costa e Formoso (2006) e o Sistema Last Planner de Controle da Produção. Embora este trabalho seja focado no processo de montagem de estruturas de aço pré-fabricadas, o mesmo enfatiza a necessidade de integrar à gestão do processo de montagem decisões relativas aos processos de projeto e fabricação das peças. O ponto de partida para o desenvolvimento desta pesquisa foi a demanda de uma empresa de sistemas construtivos de aço em aumentar a confiabilidade dos prazos de montagem de suas obras.

\section{PCP no ambiente da construção}

Laufer e Tucker (1987) descrevem o processo de PCP com base em duas dimensões, uma horizontal e outra vertical. De acordo com os referidos autores, a dimensão horizontal é composta por dois ciclos: o de planejamento e controle e o de preparação e avaliação do processo. Para Formoso et al. (1999), enquanto o primeiro ocorre de maneira contínua e está relacionado as atividades mais operacionais, tais como a coleta de dados, a elaboração de planos, a difusão de informação e a realização de ações corretivas, o segundo ciclo é marcado por momentos específicos, tal como o término de alguma etapa importante do empreendimento ou início de novos empreendimentos.

Com relação à dimensão vertical do processo, em função da incerteza e variabilidade inerentes aos empreendimentos de construção, Laufer e Tucker (1987) propõem que o processo seja dividido em diferentes níveis hierárquicos. Na manufatura, é comum a divisão em três níveis: estratégico, tático e operacional (HOPP; SPEARMAN, 1996). Entretanto, na construção civil, em geral, adota-se a designação longo, médio e curto prazo (FORMOSO et al., 1999).

Para o processo de planejamento em médio e curto prazo muitos estudos discutiram a utilização do Sistema Last Planner (BALLARD, 2000), seus benefícios e as barreiras para a implementação na construção (BALLARD; HOWELL, 1997; TOMMELEIN; BALLARD, 1997; BALLARD; HOWELL, 1998; FORMOSO et al., 1999; CODINHOTO, 2003; SOARES, 2003; VIANA, 2015). O SLP tem sido associado à implementação de alguns conceitos e princípios de Produção Enxuta na construção. Os escopos dos níveis de planejamento de médio e curto prazo são descritos a seguir:

(a) o planejamento de médio prazo, denominado por Ballard (1997, 2000) de look-ahead planning, vincula o planejamento de longo prazo ao de curto prazo. Em geral é móvel e com um horizonte que varia entre quatro e doze semanas (BALLARD; HOWELL, 1998). Neste nível, é realizada a identificação e remoção de restrições, tais como disponibilidade de recursos físicos (material, mão de obra ou equipamentos), ou financeiros, necessidade de informações de projeto, instalações provisórias, entre outros. Tais restrições, se não disponibilizadas a tempo, na quantidade e especificação corretas, impedem a execução das atividades dentro de condições adequadas (CODINHOTO, 2003); e

(b) o planejamento de curto prazo ou operacional tem o papel de orientar diretamente a execução da obra, sendo caracterizado pela atribuição de pacotes de trabalho às equipes operacionais, através de um processo participativo, realizado por meio de reuniões semanais (BALLARD; HOWELL, 1997). O planejamento neste nível deve ter forte ênfase no engajamento das equipes com as metas estabelecidas, sendo denominado também de planejamento de comprometimento (commitment planning) (BALLARD, 2000; BALLARD; HOWELL, 1998).

Dois importantes indicadores são obtidos a partir da aplicação do planejamento de curto prazo: o PPC (Percentagem da Programação Concluída), que é a relação entre o número total de tarefas concluídas na semana e o número total de tarefas programadas; e o percentual de causas da não conclusão dos pacotes de trabalho.

IBERTRAND, J. W. M.; WORTMANN, J. C.; WIJ INGAARD, J. Production Control: a structural and design oriented approach. Amsterdam: Elsevier, 1990. 
Ballard e Howell (1997) afirmam que o SLP é primeiro passo para a estabilização da produção, pois por meio deste modelo é possível aumentar a confiabilidade da execução das atividades no curto prazo, por meio da criação de uma janela de confiabilidade. De fato, o planejamento e controle de médio prazo permite estabilizar os fluxos de recursos no processo de produção. Neste contexto, planeja-se na reunião de curto prazo o que se pode fazer, ao invés do que deveria ser feito. Pode-se afirmar que o Sistema Last Planner adota o conceito de produção puxada mais amplo, proposto por Hopp e Spearman (1996), segundo o qual um sistema puxado é aquele que autoriza a realização de uma tarefa em função do status do sistema, em oposição ao sistema empurrado, no qual a execução de uma tarefa é planejada a partir de uma projeção da demanda. Assim, o LPS cria mecanismos para puxar atividades de produção e para fornecimento de recursos, nos níveis de curto e médio prazo.

A estabilidade básica tem sido descrita como um estado que deve ser buscado pelo sistema de produção para que se consiga iniciar a implementação de conceitos Produção Enxuta, possuindo três componentes fundamentais:

(a) aumento da confiabilidade na disponibilização de recursos (material, mão de obra, máquinas e método) (SMALLEY, 2005);

(b) redução da variabilidade dos processos (SMALLEY, 2005; LIKER; MEIER, 2007; SAMANIEGO; GRANJA; PICCHI, 2006); e

(c) melhoria contínua (LIKER; MEIER, 2007; SAMANIEGO; GRANJA; PICCHI, 2006) e introdução do trabalho padronizado (SMALLEY, 2005).

Bulhões (2009) aponta a implementação do planejamento de médio prazo como uma etapa inicial para se estabelecer a estabilidade básica, antes de se implementar fluxo contínuo em obras de montagem de estrutura pré-fabricada em concreto armado.

Em que pese o sucesso do Sistema Last Planner em diferentes países, no nível de planejamento e controle de longo prazo ainda é comum a utilização de métodos tradicionais de planejamento, como por exemplo, o método do caminho crítico (CPM), principalmente no planejamento de longo prazo (DAVE et al., 2015). As deficiência dos métodos de planejamento baseados no CPM são amplamente discutidas na literatura, podendo ser destacados a falta de integração dos diferentes níveis gerenciais, a não explicitação de atividades que não agregam valor, e a pouca ênfase na continuidade das tarefas e a visualização dos fluxos (DAVE et al., 2015; LAUFER; TUCKER, 1987)

Por outro lado, a Linha de Balanço (Line of Balance - LOB) apresenta-se como uma técnica de planejamento que pode contribuir para a aplicação de conceitos e princípios da Produção Enxuta, pois permite a discussão e a visualização de informações relacionadas a quando, onde e quais atividades devem ser executadas ao longo da obra (KEMMER; HEINECK; ALVES, 2008). Além disso, pode explicitar o tamanho do lote de cada atividade, o ritmo de execução, e buffers (ou folgas) de tempo para absorver a variabilidade no trabalho de diferentes equipes. Por fim, o uso da linha de balanço permite a visualização da continuidade das tarefas e eventuais conflitos entre os diferentes processos (KEMMER; HEINECK; ALVES, 2008).

Uma das limitações da Linha de Balanço diz respeito à dificuldade de se estabelecer mecanismos de monitoramento dos processos de produção. Apesar da possibilidade de se observar as diferenças entre os ritmos planejados e executados, há dificuldades para obter diretamente da LOB indicadores relacionados ao cumprimento do prazo. Neste caso, a estimativa do desvio de prazo pode ser feita de forma indireta por outros meios, tais como indicadores de avanço físico ou de desvio de ritmo. Porém, o controle da produção na construção civil deve ser efetiva nos níveis de curto e médio prazo, conforme prescrito no sistema Last Planner, com base em indicadores de aderência entre diferentes níveis de planejamento, eficácia na remoção de restrições ou eficácia na execução dos planos de curto prazo (usando o PPC). Assim, o presente trabalho propõe o uso combinado da LOB em conjuntos com o SLP para o planejamento e controle de sistemas préfabricados de aço.

\section{PSP no ambiente da construção}

O Projeto do Sistema de Produção deve ser encarado como um esforço de concepção de um sistema de produção, envolvendo uma ampla gama de decisões, incluindo layout, sequenciamento, ritmo de produção, dimensionamento de capacidade e projeto de processos críticos (SCHRAMM; COSTA; FORMOSO, 2006). Cumpre o papel de elo entre o processo de desenvolvimento do produto e o sistema de produção que o produzirá, estruturando-o de forma a tornar o processo de PCP mais simples e efetivo (SCHRAMM; 
FORMOSO, 2015). Ballard et al. (2001) afirmam que o PSP tem como papéis criar condições para controlar e melhorar o sistema de produção e fazer com que o fluxo de trabalho seja mais confiável e rápido, visando a tornar mais eficaz a entrega de valor para o cliente.

Schramm, Costa e Formoso (2006) propuseram um modelo para o desenvolvimento do PSP com base em estudos realizados em empreendimentos habitacionais de interesse social, cujas etapas são:

(a) definição da sequência de execução e dimensionamento dos recursos de produção da unidade-base: nesta etapa é realizada a definição da sequência de execução da unidade-base (unidade repetitiva) e de prédimensionamento dos recursos utilizados na sua execução. Também são tomadas decisões relacionadas ao nível de integração vertical, quais materiais ou processos serão executados pela empresa ou adquiridos de fornecedores externos, bem como a seleção dos materiais, dos sistemas construtivos e dos equipamentos a serem utilizados;

(b) estudos dos fluxos de trabalho da unidade-base: nessa etapa busca-se estabelecer os fluxos de trabalho na unidade-base, que se referem ao conjunto de operações realizadas pelas equipes de trabalho na sua execução com relação as dimensões espaço/tempo, identificando possíveis interferências entre equipes. Pode-se utilizar a Linha de Balanço para representar este fluxo;

(c) definição da estratégia de execução do empreendimento: nesta etapa são geralmente simuladas e analisadas alternativas de execução, formalizadas no plano de ataque do empreendimento, dentre as quais a mais adequada é escolhida, em função sobretudo de aspectos como: impacto no prazo final do empreendimento, limites de capacidade de produção e viabilidade financeira da opção escolhida; e

(d) estudo dos fluxos de trabalho no empreendimento: as informações provenientes do estudo dos fluxos de trabalho na unidade-base e do plano de ataque do empreendimento permitem a elaboração do estudo dos fluxos de trabalho no empreendimento, que pode também ser realizado utilizando a LOB. O objetivo principal é considerar um plano que permita um fluxo ininterrupto das equipes de produção, a partir da sincronização entre processos.

O modelo de PSP proposto por Schramm, Costa e Formoso (2006) foi adaptado para outros tipos de empreendimentos (RODRIGUES, 2006), sendo utilizado como referência no presente trabalho para realizar o Projeto do Sistema de Produção.

\section{Método de pesquisa}

\section{Estratégia e delineamento da pesquisa}

O presente trabalho adotou design science research como abordagem metodológica, a qual pode ser definida como um procedimento de pesquisa para produzir construções inovadoras, com intenção de resolver problemas encontrados no mundo real, e também fazer contribuições teóricas para uma determinada área de conhecimento (LUKKA, 2003). Adotou-se a pesquisa-ação como estratégia de pesquisa, mas não em seu formato original, proveniente das Ciências Sociais, de caráter eminentemente descritivo, mas considerando sua orientação prescritiva, adotada em alguns trabalhos anteriores (VAN AKEN, 2004; JARVINEN, 2007), posicionada como design science research.

Dick (1992) afirma que a pesquisa-ação tem dois objetivos: a ação para trazer mudança nas organizações e a pesquisa para aumentar o entendimento do tema em estudo. Eden e Huxham (1996) afirmam que uma dimensão importante desta estratégia de pesquisa é a existência de intervenção do pesquisador na organização estudada, mediante um processo cíclico composto por diagnóstico, planejamento da ação, ação, avaliação e reflexão. Segundo os mesmos autores, a partir da realização dos ciclos de aprendizagem, as soluções são refinadas.

O resultado final da pesquisa incluiu a descrição da estrutura e do funcionamento do novo sistema de PCP resultante do processo de mudança. Além disso, ao contrário do que ocorre em trabalhos de pesquisa-ação com abordagem tradicional, houve também a preocupação com a função do novo sistema, ou seja, os problemas práticos que podem ser solucionados com a sua utilização (JARVINEN, 2007).

A pesquisa foi dividida em duas grandes fases (Figura 1), a primeira para propor o conjunto de diretrizes e a segunda para implementar e refinar as mesmas. A primeira fase iniciou pela realização de um diagnóstico do processo de planejamento e controle do processo de montagem de estruturas metálicas da empresa (compreensão), com base em estudos empíricos, realizados em duas obras distintas (A e B). Buscou-se 
entender os fluxos de informações e de materiais entre a fábrica e a obra, e também a relação desses fluxos com o processo de montagem das obras.

Após, foram realizados três estudos (obras C, D e E), nos quais os sistemas de planejamento e controle da montagem foram implementados e refinados. Nos estudos empíricos C e D foram implementadas melhorias no planejamento e controle do processo de montagem, incluindo a elaboração do PSP e a implementação de alguns elementos do Sistema Last Planner. Buscou-se aumentar a confiabilidade do processo de montagem e entender as causas das falhas de planejamento. Após a realização dos estudos C e D, foi realizado o estudo empírico E, no qual foram implementadas algumas melhorias propostas nos estudos anteriores.

Ao final da primeira fase foi realizada uma análise cruzada dos dados dos estudos C, D e E, e foram propostas, de forma preliminar as diretrizes para o planejamento e controle da produção. Foram analisados três grupos de dados obtidos durante a realização destes três estudos:

(a) dados utilizados para elaboração da Linha de Balanço: diagramas de precedência das atividades; planilhas de sequenciamento, nas quais se definiam os lotes de produção e de transferência, tempos de ciclo, tamanho da equipe; e o layout do canteiro;

(b) dados gerados pelo controle da produção nos níveis de longo, médio e curto prazos: indicador de avanço físico, índice de remoção de restrições (IRR) e percentagem de pacotes concluídos (PPC), e as causas da não conclusão dos pacotes de trabalho; e

(c) indicador de aderência ao lote de entrega e ao lote de planejamento, que se refere à aderência entre o prazo previsto e o prazo real de entrega dos lotes de materiais na obra.

No caso da obra E, foi também utilizado o plano logístico de entrega de lotes de materiais, que incluía buffers de tempo para minimizar o efeito de atrasos no planejamento de montagem da obra. Além disso, neste último estudo, foram analisadas a aderência dos prazos de entrega dos lotes de materiais produzidos pela fábrica da empresa, e também a relação entre os lotes entregues e as respectivas composições de materiais, como, por exemplo, o peso das peças.

\section{Figura 1 - Delineamento da pesquisa}

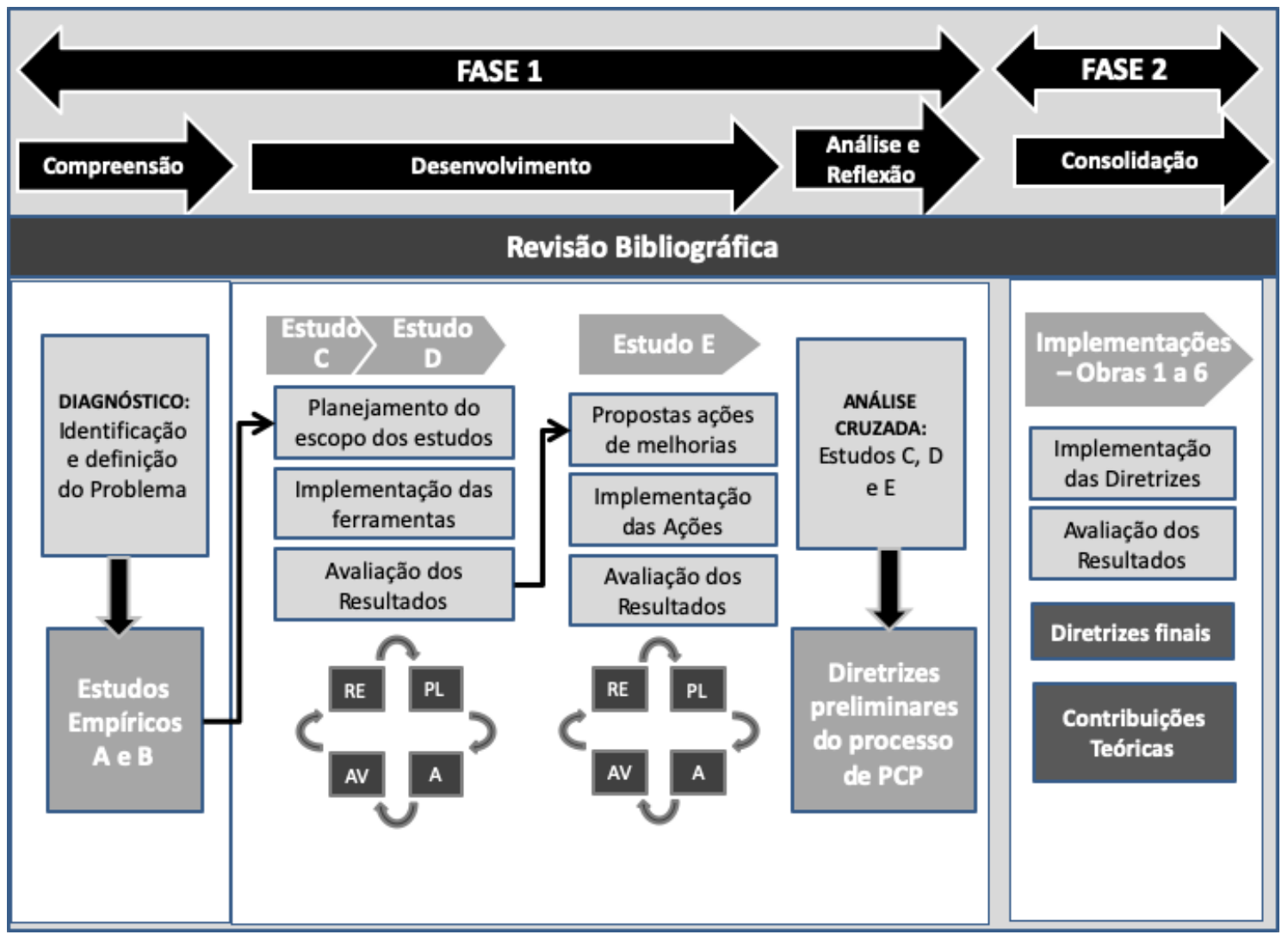


Os resultados dessa análise foram apresentados em um workshop, no qual participaram os principais intervenientes do processo de PCP da empresa. O objetivo desse workshop foi promover a discussão sobre as possíveis melhorias e novas soluções a serem implementadas no processo de PCP da empresa.

A segunda fase, denominada de consolidação, foi caracterizada pela implementação das diretrizes propostas, sem a participação de um pesquisador desempenhando o papel de facilitador, com o objetivo de testá-las e refiná-las. Nessa fase os próprios funcionários da empresa foram responsáveis por conduzir o processo de implementação nas obras. Um dos autores do presente trabalho fazia parte desta equipe de funcionários. Coube à equipe de pesquisa analisar os dados fornecidos pela empresa, referentes a seis obras (1 a 6).

Ao final do estudo, foram propostas as diretrizes finais para planejar e controlar o processo de montagem de sistemas pré-fabricados metálicos. Por fim, foi realizada uma reflexão sobre o aprendizado ocorrido no processo de desenvolvimento da pesquisa, com o objetivo de propor adaptações nas ferramentas e nos conceitos utilizados, para o contexto estudado.

\section{Fontes de evidência}

Ao longo das diferentes etapas da pesquisa, foram utilizadas múltiplas fontes de evidência, conforme sugerido por Yin (2002), para aumentar a confiabilidade dos dados. O Quadro 1 apresenta informações sobre as fontes de evidência utilizadas.

\section{Caracterização da empresa e das obras estudadas}

A empresa envolvida neste estudo tem como escopo de atuação o projeto, fabricação e montagem de sistemas pré-fabricados de aço, incluindo estruturas metálicas e, algumas vezes, vedações verticais, coberturas e componentes de ventilação. Durante a realização do estudo, a empresa possuía cerca de 2000 empregados, 3 plantas de fabricação de componentes e em torno de 100 contratos simultâneos. A escolha da empresa deveuse ao interesse da mesma em participar da pesquisa e também pelo fato de que a empresa estava implementando um programa de melhorias de suas operações com base na filosofia da Produção Enxuta.

\section{Quadro 1 - Fontes de evidência utilizadas nos estudos empíricos}

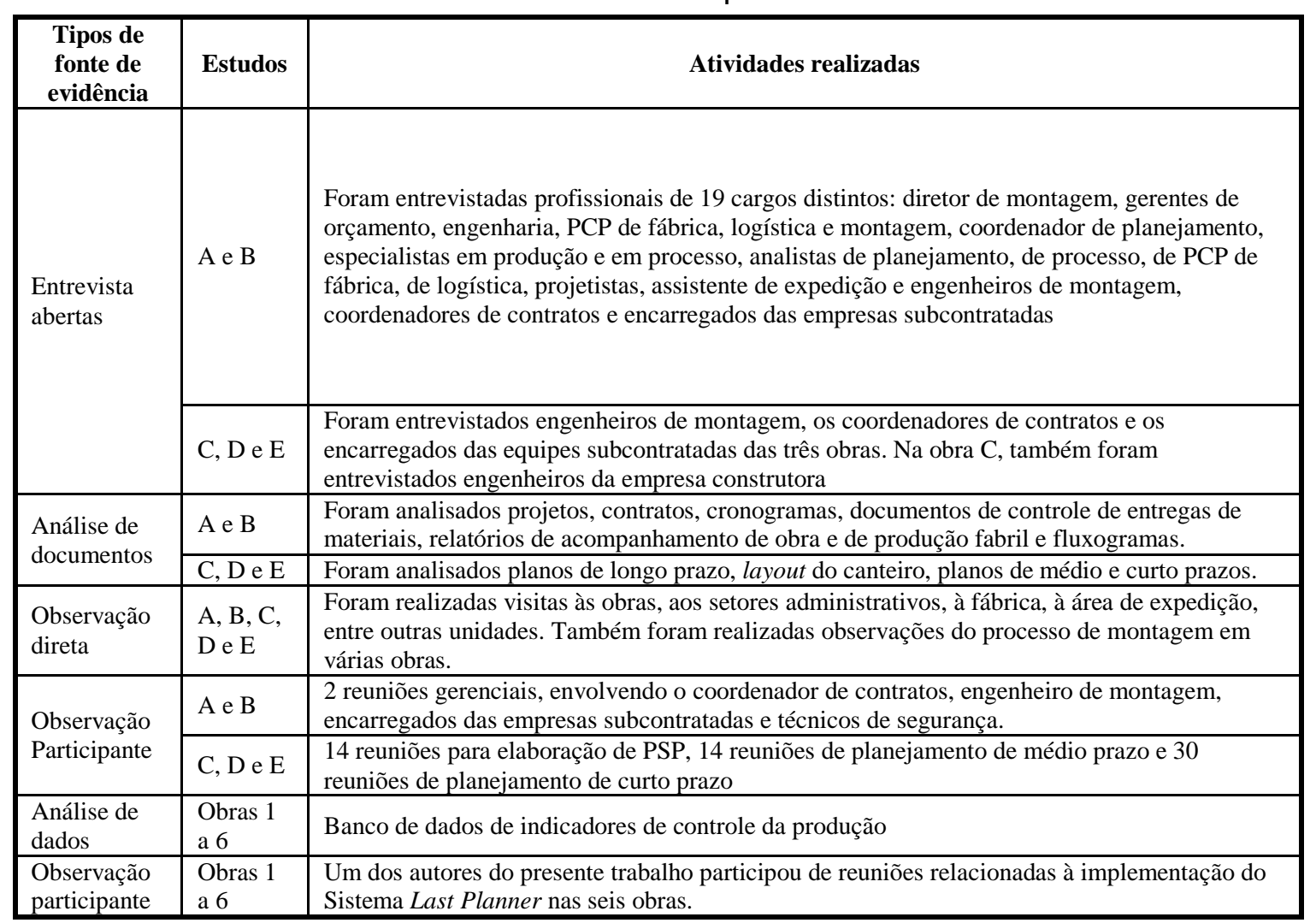


As obras da empresa eram normalmente contratadas por clientes privados e tinham um prazo de execução relativamente curto. Era adotada a prática de dividir os empreendimentos em etapas e subetapas. Esta tarefa era realizada pelo setor planejamento e tinha como objetivo reduzir o tamanho do lote e o tempo de ciclo dos processos de projeto, fabricação e montagem. Assim, a partir da subdivisão em etapas e subetapas, todos os setores deveriam planejar as suas atividades com base na sequência estabelecida pelo setor de planejamento, a partir dos dados contratuais definidos com o cliente final. Cada subetapa representava um conjunto de componentes que poderiam ser montados em obra de forma independente das demais. As Tabelas 1 e 2 apresentam o prazo, área construída e número de etapas das obras estudadas nos estudos empíricos C, D e E e nas obras da Fase 2 da pesquisa, respectivamente.

A empresa classificava os empreendimentos no início do processo de desenvolvimento do produto segundo as suas características de complexidade e sua tipologia construtiva, em três grandes categorias:

(a) tipo A: inclui os centros de distribuição, supermercados e galpões para locação, considerados como obras de menor complexidade, pois há mais padronização de componentes. Normalmente, possuem um curto prazo de montagem, entre 30 a 60 dias, com exceção de obras com áreas maiores, que, em geral, tem prazos em torno de 120 dias;

(b) tipo B: referem-se a obras de médio nível de complexidade, destinadas à instalação de indústrias, que possuem elevadas cargas estruturais. Estes empreendimentos são normalmente compostos por um galpão principal e mais alguns anexos, tais como pontes rolantes, mezaninos e plataformas, entre outros. São caracterizadas por prazos de montagem intermediários, entre 60 a 180 dias; e

(c) tipo C: são obras mais complexas e menos padronizadas, tais como aeroportos e shopping centers, que possuem prazos de montagem mais longos, a partir de 180 dias.

No diagnóstico realizado nas obras A e B, constatou-se que o processo de PCP das obras possuía características de um processo tradicional: centralização da tomada de decisão, informalidade no fluxo de informações, excesso de detalhamento dos planos de longo prazo e pouca participação dos envolvidos. Não eram realizados, também, os planejamentos de médio e curto prazos. Além disto, os dados das obras indicaram alguns problemas relacionados ao produto, que dificultavam o processo de montagem na obra. Muitas vezes esses problemas tinham a causa raiz em processos de outros setores da empresa.

Foi observado, também, que as informações relacionadas às divergências entre projeto e produto, obtidas em obra, eram pouco aproveitadas, não existindo um processo sistemático de feedback entre os setores. Assim, a definição do plano de longo prazo detalhado, em momento muito anterior ao início da montagem obra, e o fluxo de informações ineficaz entre os setores contribuíam para que cada setor executasse suas atividades de forma isolada.

Tabela 1 - Caracterização das obras dos estudos C, D e E

\begin{tabular}{c|c|c|c}
\hline Características & Estudo C & Estudo D & Estudo E \\
\hline Prazo de montagem (dias úteis) & 64 & 86 & 80 \\
Área (m²) & 12.370 & 32.000 & 24.171 \\
Quantidade de Etapas & 5 & 8 & 5 \\
\hline
\end{tabular}

Tabela 2 - Caracterização das Obras 1 a 6

\begin{tabular}{c|c|c|c|c|c|c}
\hline Características & Obra 1 & Obra 2 & Obra 3 & Obra 4 & Obra 5 & Obra 6 \\
\hline $\begin{array}{c}\text { Prazo de montagem } \\
\text { (dias corridos) }\end{array}$ & $\begin{array}{c}\text { Superior } \\
\text { a 6 meses }\end{array}$ & 97 dias & 4 meses & 3 meses & 6 meses & 3 meses \\
\hline Área (m2) & 80.430 & 12.451 & 43.000 & 7510 & 52197 & 22000 \\
\hline Quantidade de Etapas & 19 & 7 & 18 & 3 & 10 & 9 \\
\hline
\end{tabular}




\section{Resultados}

\section{Estudos empíricos C e D}

Nos estudos empíricos C e D foram elaborados os projetos dos sistemas de produção para cada uma das obras. No entanto, o escopo do PSP foi bastante limitado. A tecnologia construtiva já era consolidada e a sequência de execução das principais etapas do processo de montagem já estavam pré-definidas e formalizadas, por meio dos cronogramas definidos nos contratos com os clientes.

Assim, os projetos dos sistemas de produção desenvolvidos nestes estudos focaram-se em definições especificamente de obra, tal como o layout do canteiro, que determinava os locais de estocagem de componentes de cada subetapa, a fim de facilitar a logística envolvida no processo de montagem. Durante a elaboração do PSP, também foram realizadas discussões com a equipe de gestão da obra para definição da sequência de montagem das subetapas e dimensionamento da capacidade de produção de equipes e equipamentos. As informações de produtividade utilizadas foram fornecidas pelo engenheiro de montagem e encarregados das equipes de trabalho. A partir destas informações foram considerados diferentes cenários para a execução do empreendimento, com a utilização da Linha de Balanço. Na sequência, os cenários foram analisados e, no final, uma LOB, com o cenário escolhido pela equipe, passou a ser utilizada como o plano de longo prazo de montagem na obra.

A partir dos resultados das implementações realizadas nos estudos C e D, constatou-se a dificuldade em alterar a composição das equipes, a fim de balancear os diferentes ritmos de produção, pois as empresas de montagem eram subcontratadas e tinham autonomia sobre essa decisão. Em função disso, buscou-se melhorar o sequenciamento das atividades visando a utilizar melhor os recursos disponíveis. Observou-se também a necessidade de envolver representantes de outros setores na elaboração do PSP de montagem, a fim de ampliar o escopo de decisões nesta etapa. Como as atividades da empresa eram bastante verticalizadas, havia um ambiente propício para um esforço de integração dos sistemas de planejamento dos setores de engenharia de projetos, manufatura, logística e montagem.

O planejamento de médio prazo das obras C e D foi realizado no canteiro de obras, e envolvia o engenheiro e o seu coordenador, os encarregados das equipes de montagem e a pesquisadora. Houve dificuldades na implementação deste nível de planejamento, não sendo possível obter estoques de atividades totalmente livres de restrições, para serem utilizadas no planejamento de curto prazo. Na Tabela 3 estão apresentados os indicadores obtidos nas obras C e D. Pode-se observar que o IRR do estudo C foi de $74 \%$ e o do estudo D foi de 29,33\%. O baixo índice de remoção das restrições na obra D foi em função da dificuldade que a gerência de obra tinha em remover as restrições que tinham origem em outros setores da empresa, particularmente aquelas relacionadas à entrega de materiais em obra. Estas restrições dependiam, por vezes, do sequenciamento da fabricação e do planejamento da entrega de material, cujas decisões eram tomadas de maneira independente, nos setores responsáveis.

Tabela 3 - Indicadores de planejamento e controle de médio e curto prazo - Estudos C e D

\begin{tabular}{|c|c|c|}
\hline & Estudo C & Estudo D \\
\hline & \multicolumn{2}{|c|}{ Médio Prazo } \\
\hline IRR médio & $74 \%$ & $29,33 \%$ \\
\hline \multirow[t]{2}{*}{$\begin{array}{l}\text { Quantidade média de restrições } \\
\text { identificadas por reunião }\end{array}$} & 56 & 23 \\
\hline & \multicolumn{2}{|c|}{ Curto prazo } \\
\hline PPC médio & $68,90 \%$ & $47 \%$ \\
\hline $\begin{array}{l}\text { Quantidade média de pacotes } \\
\text { definidos por reunião }\end{array}$ & 13 & 9 \\
\hline \multicolumn{3}{|c|}{ Causas da não conclusão dos pacotes de trabalho } \\
\hline $\begin{array}{c}\text { Causas internas originárias da } \\
\text { obra }\end{array}$ & $47,30 \%$ & $67,21 \%$ \\
\hline Causas externas & $47,30 \%$ & 8,205 \\
\hline $\begin{array}{l}\text { Causas originárias de outros } \\
\text { setores }\end{array}$ & $5,40 \%$ & $24,59 \%$ \\
\hline
\end{tabular}


Como as restrições não eram removidas, a equipe de gestão das obras determinava a inclusão, no plano de curto prazo, de pacotes de trabalho que ainda possuíam restrições. Assim, iniciava-se a execução desses pacotes de trabalho e tentava-se efetuar a remoção das restrições durante a realização da atividade. No entanto, frequentemente não era possível remover tais restrições e a execução da atividade era interrompida, aumentando a quantidade de trabalho em progresso em obra e reduzindo o PPC, conforme pode ser observado na Tabela 3. Os pacotes de trabalho eram definidos a partir do detalhamento das atividades da LOB e depois ajustadas na reunião de curto prazo, em conjunto com as equipes de montagem.

A dificuldade na implementação do planejamento de médio prazo e na remoção das restrições refletiu no desempenho do planejamento de curto prazo, principalmente na obra D. Como pode ser observado na Tabela 3 , os valores do PPC médio das obras foram de $68,90 \%$ para a obra C e de $47 \%$ para a obra D, indicando um baixo grau de confiabilidade do sistema de planejamento e controle do processo de montagem. Observa-se também na Tabela 3, que os problemas cuja a causa raiz eram internas à obra, foi de 47,30\% na obra C, e de $67,21 \%$ na obra D. Com relação aos problemas com causas externas, ou seja, originarias em outros setores da empresa, na obra C foi de $5,40 \%$ e na obra D de $24,59 \%$. Isso pode justificar os baixos valores do IRR e do PPC na obra D.

Na Figura 2 estão apresentadas as causas acumuladas da não conclusão dos pacotes de trabalho na obra D. Observa-se que o problema relacionado com falta de material foi o mais frequente, com 22 ocorrências, causadas principalmente pelo atraso de entregas e pela entrega de material em desacordo com a sequência planejada. Outros problemas observados foram: baixa qualidade, falhas no planejamento, estimativa de produtividade superior ao ritmo real de execução, falhas de projetos que geravam a necessidade de ajustes de peças no canteiro de obras, dentre outros.

O problema relacionado com a falta de material identificada na Obra D (Figura 2) foi também evidenciado no indicador de aderência ao lote de entrega. Observou-se que nesta obra a entrega de subetapas de materiais não seguiu a sequência planejada, resultando em pouca aderência ao lote de entrega, como ilustram as Figuras 3 e 4.

Conforme pode ser observado na Figura 3, todos os componentes da primeira subetapa de estruturas deveria estar em obra no dia 20/06. Porém, as peças começaram a chegar a partir desse dia e foram sendo entregues em frações de lote, tendo sua entrega concluída apenas no dia 20/07. Esses atrasos aconteceram ao longo das várias subetapas e contribuíram negativamente para a eficácia do PCP, resultando em atrasos na obra. No entanto, apesar destes atrasos nas entregas, as duas primeiras subetapas de telhas (Figura 4) começaram a ser entregues antes do prazo previsto.

Os atrasos na entrega dos lotes de materiais demonstram um descompasso entre o que é produzido na fábrica e o que é necessário para a montagem da obra, deixando claro que o planejamento da produção de componentes não está vinculada as necessidades de montagem da obra. Em função disto, a entrega de materiais ocorreu de maneira empurrada, destacando a falta de aderência entre as atividades que são planejadas e formalizadas no plano de longo prazo da obra e as atividades que são, de fato, realizadas pelos setores. Ressalta-se, assim, a necessidade de melhorias do PSP, que visem a integração dos processos realizados por diferentes setores da empresa.

\section{Figura 2 - Causas da não conclusão dos pacotes de trabalho - Obra D}

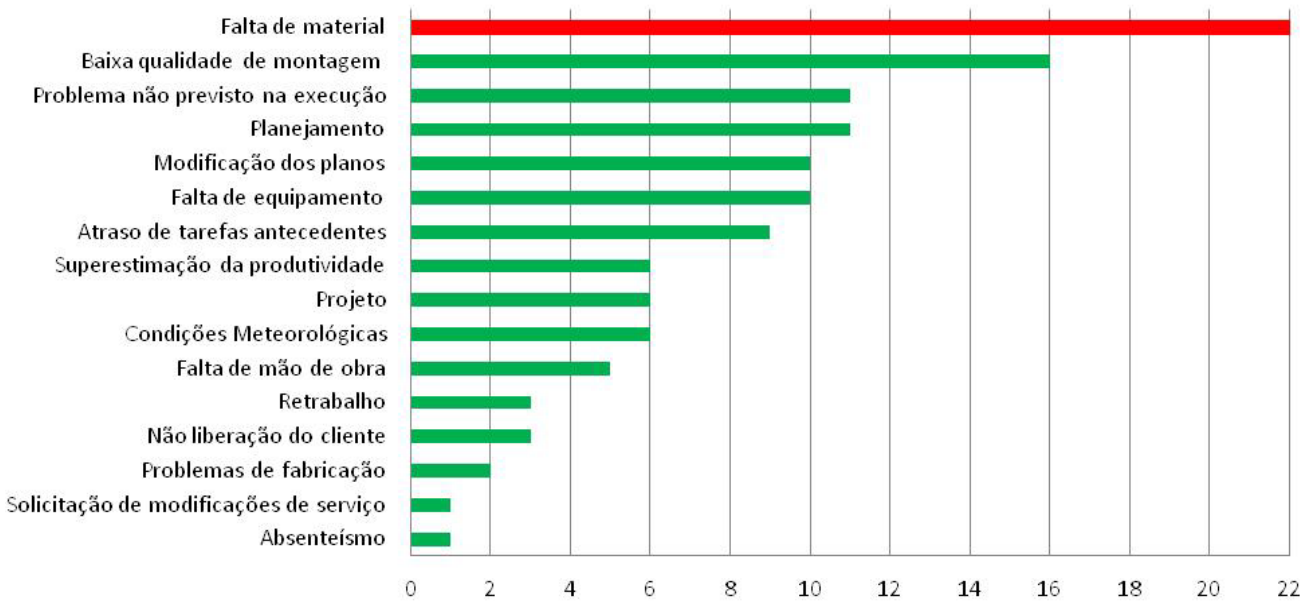


Figura 3 - Aderência ao lote de entrega - obra D - subetapa de estruturas

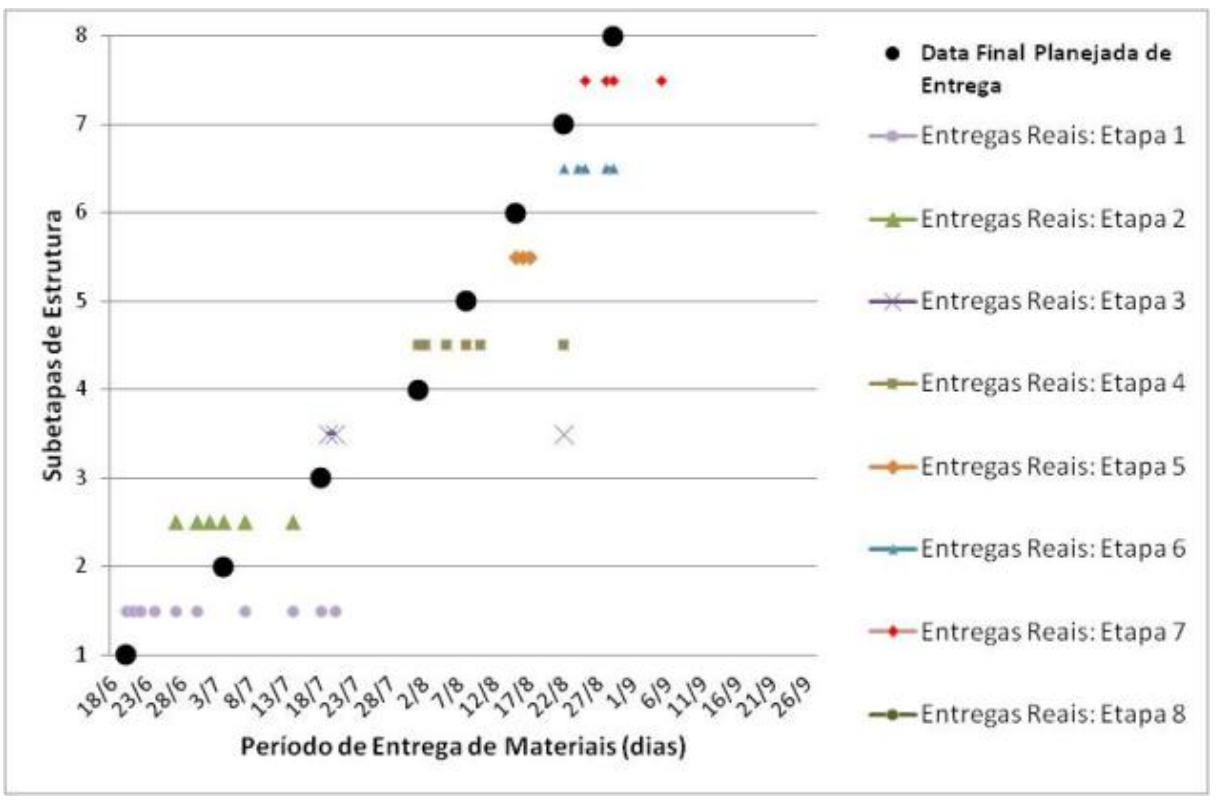

Figura 4 - Aderência ao lote de entrega - obra D - subetapa de telhas

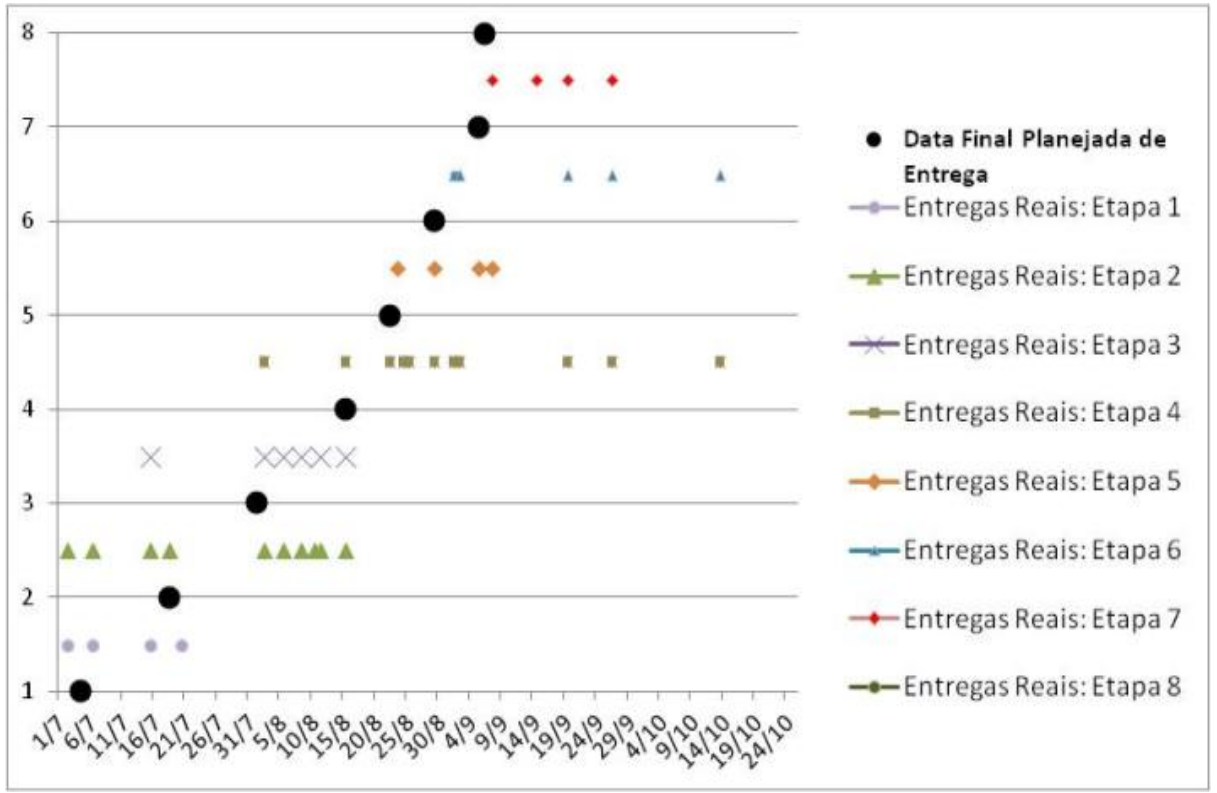

Como conclusão dos estudos C e D, pode-se afirmar que a implementação do PSP e do SLP contribuiu para aumentar a confiabilidade do PCP somente em obras cujas principais restrições relacionam-se com decisões que podem ser tomadas apenas pela gerência da obra, como ocorreu no estudo C. Por outro lado, obras nas quais as restrições relacionam-se com decisões que são tomadas por diferentes setores da empresa, o PSP e o planejamento de médio prazo deveriam ter seus escopos alterados, tanto em relação ao início do processo, quanto aos setores envolvidos. Ou seja, a elaboração do PSP e do planejamento de médio prazo não deve se limitar somente ao processo de montagem, mas também integrar a engenharia (projeto), a manufatura e a logística.

\section{Estudo empírico E}

A partir das reflexões feitas a partir dos resultados dos estudos C e D, foram definidas as seguintes ações de melhorias para serem implementadas no estudo empírico E: 
(a) realizar um processo de PCP integrado, envolvendo os setores de planejamento, engenharia, manufatura, logística e montagem;

(b) envolver o cliente nas decisões de sequenciamento e plano de ataque da obra; e

(c) ampliar o escopo do PSP, que deve conter: dimensionamento da capacidade dos recursos de produção, equipes e equipamentos, definição da sequência de execução, definição do tamanho dos lotes de montagem, reduzindo-os, a partir de uma nova divisão das etapas em subetapas, definição dos fluxos de trabalho com o uso da LOB, definindo cenários alternativos para diferentes planos de ataque e layout do canteiro.

Nesse estudo foram elaborados três planos de longo prazo, com diferentes cenários, os quais continham os seguintes elementos: Linha de Balanço, histograma de recursos (materiais e mão de obra) e uma lista de restrições para serem removidas pelos diferentes setores, antes do início da montagem da obra. Após a elaboração dos planos, as informações foram utilizadas no planejamento de cada subetapa da obra nos setores de engenharia (projeto) e fabricação, a fim de possibilitar a entrega de lotes de materiais no canteiro de obra no prazo. Além disso, foram gerados os seguintes documentos: histogramas de mão-de-obra e equipamentos a serem utilizados para a contratação da equipe de montagem; e o plano de carregamento de materiais, para possibilitar que as subetapas de materiais fossem entregues completas em obra e na data planejada.

Na fase de implementação das diretrizes preliminares, ocorreram muitas alterações no plano de montagem, por demandas provenientes do cliente. Entre as principais alterações destacam-se o atraso no início da montagem dos pilares pré-moldados de concreto e a mudança no sequenciamento dessa montagem, que foi executada de maneira diferente ao plano de ataque previamente acordado para a estrutura metálica de cobertura e o fechamento lateral. Assim, a sequência de entrega das subetapas de materiais da estrutura metálica ficou diferente da sequência de montagem planejada inicialmente, não sendo possível alterar a sequência de produção de componentes na fábrica. Como consequência, os materiais continuaram sendo entregues na sequência originalmente definida no plano de longo prazo, resultando em atrasos na montagem da obra e gerando grandes estoques de materiais no canteiro de obras.

A partir desse novo contexto, revisou-se o plano de longo prazo da montagem, de forma a adaptá-lo ao sequenciamento de montagem da obra e elaborou-se um detalhamento do layout do canteiro. Também, iniciouse o planejamento de médio e curto prazo. No entanto, o processo de PCP foi realizado apenas nas primeiras semanas da obra, não gerando resultados quantitativos para comparação com os indicadores dos outros estudos.

Como conclusão do estudo E, observou-se que, embora tenham ocorrido melhorias no processo de PCP, principalmente em relação à integração entre os diferentes setores da empresa, não foi possível implementar totalmente as diretrizes propostas para o estudo. Neste ponto, concluiu-se que o processo de PCP, mais especificamente o planejamento de médio prazo deveria ser iniciado antes do início da obra. Esta ação aumenta a flexibilidade do sistema produtivo da empresa, permitindo que seja absorvida a variabilidade e a incerteza inerente ao processo produtivo, tanto de origem interna como externa.

Portanto, os resultados obtidos indicaram que muitas melhorias ainda poderiam ser realizadas, a fim de reduzir a variabilidade dos processos. Ou seja, aumentando a estabilidade e a confiabilidade do processo produtivo da empresa, pode ser possível flexibilizar a produção dos setores à montante da montagem, a fim de puxar essa produção com base nas necessidades das obras. Assim, com base nos estudos realizados e nas discussões com gerentes e engenheiros de montagem, sugeriu-se que a empresa adotasse processos de PCP distintos, sendo elaboradas diretrizes preliminares para as três diferentes categorias de obra (A, B e C), apresentadas a seguir.

\section{Diretrizes preliminares por categorias de obras}

As diretrizes propostas, ao final da Fase, foram distintas para cada tipo de obra definido pela empresa. As mesmas estão apresentadas a seguir.

\section{Obras do tipo A}

Para obras tipo A, foi proposta a definição do PSP como mecanismo de integração dos diferentes setores da empresa. A elaboração do PCP deve ocorrer no início da fabricação das peças do empreendimento, em média 45 dias antes do início da montagem Além disso, para se flexibilizar o sistema produtivo, propõe-se a ampliação do mix de projetos prontos para serem produzidos, a partir do planejamento de um estoque de projetos de subetapas para a produção, pois, assim, haveria tempo de adequar a produção da fábrica às necessidades da obra. Dada a similaridade de prazo (30 a 60 dias) e de aspectos construtivos entre as obras 
dessa categoria, sugere-se a implantação de PSPs pré-definidos, a serem adaptados às peculiaridades de cada obra, o que pode contribuir para que a elaboração do PSP seja mais rápido e eficaz.

Assim, o plano de longo prazo deve ser elaborado a partir de um PSP pré-definido, com horizonte de tempo compreendendo todo o período de montagem. Para o planejamento de médio prazo sugere-se adotar como horizonte de tempo inicial todo o período da obra, e sua elaboração deve envolver uma equipe multifuncional, com representantes dos diferentes setores (engenharia, manufatura, logística e montagem). Esses representantes devem ser os responsáveis por controlar a execução de ações para a remoção de restrições, a fim de aumentar a sua eficácia. O plano de médio prazo pode ser utilizado para confirmar e puxar a produção da fábrica, devendo ser elaborado com antecedência de 45 dias ao início da obra.

A obra deve ser iniciada com a existência de um estoque inicial de materiais. Essa seria uma estratégia adotada com o objetivo de proteger o processo de montagem da variabilidade existente no processo de fabricação. Com relação ao planejamento de curto prazo, este deve ter a periodicidade semanal, e envolver o engenheiro de montagem e os encarregados das equipes de montagem.

\section{Obras do tipo B}

Para obras do tipo B, propôs-se que o PSP seja desenvolvido antes de iniciar a etapa de projeto, contendo as seguintes informações: plano de ataque da obra, sequência de execução e um plano com sincronizando o trabalho das diferentes equipes. Além disso, devem ser indicados os ritmos de produção das equipes e equipamentos, considerando as particularidades do projeto. Um dos produtos do PSP é o plano de longo prazo da obra.

Aproximadamente 30 dias antes do início da obra, deve ser elaborado o planejamento de médio prazo, envolvendo os representantes dos diferentes setores (engenharia, manufatura, logística e montagem). Esses representantes devem ser os responsáveis pela remoção de restrições identificadas no plano de médio prazo. Sugere-se que a cada três semanas esse plano seja revisado e que sejam planejadas as seis semanas seguintes. Uma das funções desse plano é gerenciar a sequência de produção dos materiais definida no planejado no longo prazo e as alterações necessárias que possam surgir no decorrer da montagem. Além disso, é no médio prazo que se definem as estratégias para realização das alterações necessárias.

No primeiro mês de montagem, sugere-se que o planejamento de curto prazo seja realizado duas vezes por semana, em obra. Esta recomendação deve-se ao fato de que este tipo de obra abrange empreendimentos mais complexos, sendo necessário um esforço maior de controle da produção, visando à aderência entre a sequência de montagem planejada e a executada. Além disso, a partir dos problemas observados, deve-se analisar as causas, identificar a causa raiz e propor ações para evitar que os problemas se repitam. Posteriormente, deve ser realizada apenas uma reunião semanal.

\section{Obras do tipo C}

Para obras do tipo C, sugere-se elaborar um PSP específico, de acordo com as características e necessidades de cada empreendimento, desenvolvido antes de iniciar a fase de projeto. De forma semelhante às obras incluídas na categoria B, o PSP para as obras tipo C deve ter as seguintes informações: plano de ataque da obra, sequência de execução ritmos de produção das equipes e equipamentos e o plano de longo prazo da obra.

O planejamento de médio prazo deve, também, ser iniciado antes do início de obra e deve envolver os diferentes setores. Esses representantes serão os responsáveis pela remoção de restrições identificadas no plano de médio prazo. Sugere-se que, para essa categoria de obras, a cada quatro semanas esse plano seja revisado e que sejam planejadas as oito semanas seguintes. Uma das funções desse plano é gerenciar a sequência de produção dos materiais definida no planejado no longo prazo e as alterações necessárias que possam surgir no decorrer da montagem.

Posteriormente, os demais processos de PCP devem ser desenvolvidos em obra, mantendo-se a sua função de puxar a produção da fábrica. Nessa categoria de empreendimentos, também devem realizadas, inicialmente, duas reuniões semanais para planejamento de curto prazo, reduzindo-se posteriormente para apenas uma reunião semanal em obra.

\section{Implementações realizadas pela empresa}

Na escolha das seis obras estudadas nesta etapa, procurou-se contemplar os três diferentes tipos de obra. Em cada uma das obras, a empresa procurou implementar as diretrizes preliminares apresentadas no item anterior. 
A Tabela 4 apresenta o IRR médio para cada uma das obras, sendo os valores relativamente próximos entre as obras de diferentes tipos, evidenciando que as diretrizes propostas para cada categoria de obra alcançaram níveis similares de eficácia. Analisando comparativamente as Tabelas 4 e 3, chama atenção o IRR médio de $62 \%$ obtido na obra 5 (tipo B) em comparação ao IRR médio de 29,33\% no estudo empírico D (que também era do tipo B). A partir desta comparação, é possível considerar que o escopo de PCP e PSP, proposto para este tipo de obra (B), contribuiu para melhorar o processo de identificação e remoção das restrições, por meio do envolvimento do setor de montagem e dos setores a montante (logística, manufatura e engenharia). No entanto, os valores médios de IRR podem ser considerados ainda relativamente baixos e houve muitas variações nas quantidades de restrições identificadas, sugerindo que o planejamento de médio prazo ainda não estava consolidado.

No planejamento de curto prazo, verificou-se que houve um nivelamento do índice de PPC médio, entre as obras de diferentes categorias, porém o valor médio de PPC (46\%) para conjunto de obras confirma que o processo de PCP da empresa ainda é pouco confiável (Tabela 5). Analisando as causas de não cumprimento dos pacotes de trabalho, verifica-se que ainda há muitos problemas que tem origem em outros setores da empresa, assim como incertezas que envolvem o próprio planejamento das atividades em obra.

Em suma, os resultados obtidos nas seis obras indicam que a implementação do processo de PCP ainda não tinha alcançado níveis satisfatórios. A seguir, serão listados alguns problemas observados:

(a) alta variabilidade nas atividades realizadas pelas diversas equipes de montagem: era causada principalmente pela falta de padronização das atividades no canteiro, o que dificultava a definição consistente dos pacotes de curto prazo;

(b) dificuldade no envolvimento dos líderes de frente de trabalho no PCP: percebeu-se que a falta de envolvimento desses líderes no planejamento de curto prazo fez com que houvesse pouco comprometimento das equipes com os pacotes de trabalhos planejados, resultando em baixos valores de PPC;

(c) dificuldade na sistematização do PCP na rotina das atividades em obra: os gráficos de PPC das obras indicaram tendências similares nas diferentes obras. Houve uma tendência de crescimento nas fases iniciais e intermediarias do processo de montagem das obras. Porém, nas fases finais da obra houve uma tendência de reduzir o PPC, devido a dificuldades em manter as equipes participando das reuniões de PCP e em executar as atividades programadas; e

(d) desmotivação dos participantes pelas dificuldades na remoção de restrições de materiais: apesar do grande avanço na integração do planejamento de médio prazo com os demais setores da empresa, ainda era necessário estruturar um processo de planejamento integrado consistente, envolvendo diferentes setores da empresa, para melhorar o processo de remoção de restrições. Isso se deve principalmente ao fato de a empresa ter uma grande quantidade de obras concomitantes, demandando um grande esforço para compilar em um único local as informações relacionadas às restrições de material ou projeto de todas as obras da empresa.

Por outro lado, a implementação de mudanças no processo de planejamento e controle resultou em benefícios obtidos pelas empresas, entre os quais destaca-se: aumento do domínio do processo de montagem da obra, visto que anteriormente não existia informações de controle da produção nas obras; orientação das equipes em relação as tarefas a serem executadas; aumento do controle dos processos entre os setores; aumento de produtividade; e definição clara do plano de ataque da obra, aumentando a transparência em relação aos dados de obra junto ao cliente.

Tabela 4 - Indicadores PCP Médio Prazo - Obras 1 a 6

\begin{tabular}{l|l|l|l|l|l}
\hline Obra 1 & Obra 2 & Obra 3 & Obra 4 & Obra 5 & Obra 6 \\
\hline
\end{tabular}
Médio Prazo

\begin{tabular}{c|c|c|c|c|c|c}
\hline Tipo de Obra & $\mathrm{C}$ & $\mathrm{A}$ & $\mathrm{A}$ & $\mathrm{A}$ & $\mathrm{B}$ & $\mathrm{A}$ \\
\hline IRR médio & $55 \%$ & $55 \%$ & $61 \%$ & $55 \%$ & $62 \%$ & $54 \%$ \\
\hline $\begin{array}{c}\text { Quantidade média de restrições } \\
\text { identificadas por reunião }\end{array}$ & 26,2 & 23 & 15,5 & 23 & 5 & 37 \\
\hline
\end{tabular}


Tabela 5 - Indicadores de planejamento e controle de Curto Prazo - Obras 1 a 6

\begin{tabular}{c|c|c|c|c|c|c} 
& Obra 1 & Obra 2 & Obra 3 & Obra 4 & Obra 5 & Obra 6 \\
\cline { 2 - 7 } & \multicolumn{7}{c}{ Curto prazo } \\
\hline Categoria & $\mathrm{C}$ & $\mathrm{A}$ & $\mathrm{A}$ & $\mathrm{A}$ & $\mathrm{B}$ & $\mathrm{A}$ \\
\hline PPC médio & $58 \%$ & $51 \%$ & $45 \%$ & $52 \%$ & $66 \%$ & $66 \%$ \\
\hline $\begin{array}{c}\text { Quantidade média de } \\
\text { pacotes definidos por } \\
\text { reunião semanal }\end{array}$ & 15 & 6 & 10 & 6 & 7 & 9 \\
\hline \multicolumn{6}{c}{ Causas da não conclusão dos pacotes de trabalho } \\
\hline $\begin{array}{c}\text { Causas internas originárias } \\
\text { da obra }\end{array}$ & $54 \%$ & $40 \%$ & $34 \%$ & $46 \%$ & $8,33 \%$ & $19 \%$ \\
\hline Causas externas & $28 \%$ & & $45 \%$ & $47 \%$ & $33,33 \%$ & $35 \%$ \\
\hline $\begin{array}{c}\text { Causas originárias de } \\
\text { outros setores }\end{array}$ & $18 \%$ & $60 \%$ & $21 \%$ & $7 \%$ & $58,33 \%$ & $46 \%$ \\
\hline
\end{tabular}

\section{Discussão e contribuições}

Como resultado final da fase 2, foi proposto um refinamento das diretrizes preliminares. As diretrizes finais (Quadro 2) podem ser consideradas como complementares aos elementos já consolidados do Sistema Last Planner e do PSP, apresentados na revisão bibliográfica. Tais diretrizes foram divididas em cinco categorias, sendo que as diretrizes são distintas para cada tipo de obra nas três últimas categorias:

(a) planejamento integrado de médio prazo, envolvendo os setores de projeto, fabricação, logística e montagem;

(b) planejamento logístico de cargas, incluindo a definição de lotes e elaboração de planos de carga;

(c) projeto do sistema de produção;

(d) planejamento e controle da montagem em nível de médio prazo; e

(e) planejamento e controle da montagem em nível de curto prazo.

No que se refere a contribuições teóricas do presente trabalho, podem ser destacadas as seguintes:

(a) dado o elevado grau de complexidade dos sistemas pré-fabricados do aço do tipo ETO, devido à incerteza e variabilidade no processo de montagem e à elevada interdependência entre as obras e os processos de projeto, fabricação e logística, existe a necessidade de um sistema de planejamento e controle integrado e baseado em um esforço de concepção do sistema de produção de cada obra. Assim, há necessidade de promover a integração entre os diferentes setores e diferentes níveis hierárquicos, por meio de trocas de informação, e utilizar uma abordagem participativa e descentralizada da gestão da produção. O Sistema Last Planner tem um papel importante na identificação dos problemas e na proteção da produção por meio da remoção sistemática de restrições, permitindo que seja alcançada a estabilidade básica;

(b) existe também a necessidade de padronizar e tornar sistemáticos o planejamento e controle da produção nos seus diferentes níveis, sendo que os planos devem ser visuais, de fácil compreensão por todos os envolvidos;

(c) para que a logística de abastecimento dos componentes seja eficaz, é necessário puxar os processos de fabricação e logística pelo processo de montagem. Assim, considerando o conceito de produção puxada proposto por Hopp e Spearman (1996), é necessário manter informações atualizadas do status do processo de montagem e torná-las disponíveis aos diversos intervenientes; e

(d) uma das lacunas identificadas no estudo com relação à redução da variabilidade é a necessidade de abordagens mais eficazes para padronização de processos, tais como treinamento de mão de obra, a consideração do tempo de ciclo como um dos elementos do padrão, e o uso da gestão visual para detectar erros mais rapidamente. Na empresa estudada, a aplicação deste princípio foi limitada pelo fato de que o processo de montagem era definido pelas empresas subcontratadas. 
Quadro 2 - Diretrizes finais para planejamento e controle de estruturas metálicas

\begin{tabular}{|c|c|c|c|}
\hline \multicolumn{4}{|c|}{ Diretrizes para processos de PCP em obras de estrutura metálica } \\
\hline Categoria & $\mathrm{A}$ & $\mathrm{B}$ & $\mathrm{C}$ \\
\hline $\begin{array}{l}\text { Planejamento } \\
\text { Integrado } \\
\text { de Médio } \\
\text { Prazo }\end{array}$ & \multicolumn{3}{|c|}{$\begin{array}{l}\text { Instituir uma rotina mensal de planejamento que permita a troca de informações entre } \\
\text { diferentes unidades da empresa, tais como projeto, fabricação, logística e montagem, no } \\
\text { nível de planejamento de médio prazo, com relação às diversas obras da empresa. Nesta } \\
\text { rotina, as obras podem informar aos demais setores ajustes na programação da montagem, } \\
\text { enquanto os demais setores podem explicitar eventuais limitações de capacidade com } \\
\text { antecedência. }\end{array}$} \\
\hline $\begin{array}{l}\text { Planejamento } \\
\text { logístico de } \\
\text { cargas }\end{array}$ & \multicolumn{3}{|c|}{$\begin{array}{l}\text { Criar uma sistemática de planejamento de cargas que considere a sequência de montagem } \\
\text { efetivamente demandada pelas obras. A partir das demandas das obras devem ser elaborados } \\
\text { planos de carga, levando em conta a divisão da obra em etapas e subetapas de montagem, de } \\
\text { forma que não faltem peças nos lotes de montagem. }\end{array}$} \\
\hline $\begin{array}{l}\text { Projeto do } \\
\text { Sistema de } \\
\text { Produção } \\
\text { (PSP) }\end{array}$ & $\begin{array}{l}\text { A elaboração do PSP deve } \\
\text { anteceder o início da } \\
\text { fabricação de peças, para } \\
\text { permitir que a sequência de } \\
\text { fabricação seja programada } \\
\text { de acordo com as } \\
\text { necessidades da obra. Deve- } \\
\text { se também definir a } \\
\text { necessidade de um estoque } \\
\text { mínimo de projetos para } \\
\text { facilitar a programação da } \\
\text { fábrica. Para facilitar a } \\
\text { elaboração do PSP, diversas } \\
\text { decisões podem ser } \\
\text { padronizadas para algumas } \\
\text { tipologias de projeto. }\end{array}$ & $\begin{array}{l}\text { A elaboração do PSP deve } \\
\text { anteceder o início da } \\
\text { fabricação de peças, para } \\
\text { permitir que a sequência de } \\
\text { fabricação seja programada } \\
\text { de acordo com as } \\
\text { necessidades da obra. } \\
\text { Deve-se buscar a } \\
\text { sincronização de processos } \\
\text { e definir os percursos das } \\
\text { diferentes equipes e } \\
\text { programar a produção dos } \\
\text { demais setores de acordo } \\
\text { com as necessidades da } \\
\text { obra }\end{array}$ & $\begin{array}{l}\text { A elaboração do PSP deve } \\
\text { anteceder o início da } \\
\text { fabricação de peças, para } \\
\text { permitir que a sequência de } \\
\text { fabricação seja programada de } \\
\text { acordo com as necessidades } \\
\text { da obra. Neste tipo de obra, o } \\
\text { PSP tem características } \\
\text { específicas, de acordo com as } \\
\text { características e necessidades } \\
\text { de cada empreendimento. As } \\
\text { atividades dos demais setores } \\
\text { devem ser programadas de } \\
\text { acordo com as necessidades } \\
\text { da obra }\end{array}$ \\
\hline $\begin{array}{l}\text { Planejamento e } \\
\text { Controle de } \\
\text { Médio Prazo } \\
\text { da Montagem }\end{array}$ & $\begin{array}{l}\text { Dado o curto prazo da obra, } \\
\text { deve ser elaborado um plano } \\
\text { com um horizonte igual à } \\
\text { duração da obra, com a } \\
\text { identificação de todas as } \\
\text { restrições. À medida que a } \\
\text { montagem avança, a } \\
\text { identificação de restrições } \\
\text { deve ser atualizada. }\end{array}$ & $\begin{array}{l}\text { O primeiro planejamento } \\
\text { de médio prazo deve ser } \\
\text { iniciado antes do início do } \\
\text { processo de montagem. Ao } \\
\text { longo da obra, devem ser } \\
\text { feitos novos planos } \\
\text { móveis, com frequência } \\
\text { regular (por exemplo, } 2 \text { a } 3 \\
\text { semanas). }\end{array}$ & $\begin{array}{l}\text { O primeiro planejamento de } \\
\text { médio prazo deve ser iniciado } \\
\text { antes do início do processo de } \\
\text { montagem. Ao longo da obra, } \\
\text { devem ser feitos novos planos } \\
\text { móveis, com frequência um } \\
\text { pouco menor (por exemplo, } 4 \\
\text { semanas). }\end{array}$ \\
\hline $\begin{array}{l}\text { Planejamento e } \\
\text { Controle de } \\
\text { Curto Prazo da } \\
\text { Montagem }\end{array}$ & $\begin{array}{l}\text { Dado o curto prazo da obra, } \\
\text { deve ser entregue um buffer } \\
\text { dimensionado de } \\
\text { componentes. As reuniões } \\
\text { devem ser realizadas } \\
\text { semanalmente, de forma } \\
\text { regular. }\end{array}$ & $\begin{array}{l}\text { Dado o grau de complexidad } \\
\text { feitas duas reuniões semanai } \\
\text { exemplo, } 1 \text { mês), e depois re } \\
\text { semanal. }\end{array}$ & $\begin{array}{l}\text { mais elevado, devem ser } \\
\text { no início da obra (por } \\
\text { dzir para uma reunião }\end{array}$ \\
\hline
\end{tabular}

\section{Conclusões}

O objetivo do presente trabalho foi propor diretrizes para planejar e controlar o processo de montagem de sistemas construtivos de aço do tipo ETO. Estes sistemas normalmente possuem um elevado grau de complexidade, em função da variabilidade e incerteza envolvida e também pelas interdependências existentes entre unidades de produção.

O estudo envolveu um esforço inicial de compreensão aprofundada do problema, a partir de dois estudos realizados em distintas obras da empresa participante da pesquisa. Após, foram implementadas melhorias em um conjunto de obras da empresa em duas etapas. A primeira, envolvendo três obras, teve a participação de um pesquisador como facilitador do processo de implementação, enquanto a segunda, envolvendo seis obras, teve a implementação conduzida por gerentes da própria empresa.

Destaca-se que o PCP implementado trouxe benefícios para a empresa, apesar de estar restrito ao processo de montagem. Por exemplo, no estudo C, reduziu-se a parcela de atividades que não agregam valor ao produto, relacionadas às atividades de transporte e inspeção, a partir do planejamento do layout do canteiro. Ademais, 
com a implementação do processo de PCP foi possível promover um aumento da transparência no que se refere às metas do empreendimento.

Entretanto, foram identificadas diversas dificuldades a serem superadas no processo de implementação. A principal dificuldade é o fato de que existem muitas limitações quanto à remoção de restrições por parte da equipe gerencial da obra, quando as mesmas estão relacionadas à entrega de componentes em obra. Essas dificuldades eram causadas principalmente pelas restrições existentes nos processos à montante da montagem, especialmente no processo de fabricação dos produtos. Bulhões (2009), no contexto de pré-fabricação de concreto armado, também chamou atenção para a necessidade se realizar um planejamento integrado dos processos de projeto, fabricação e montagem.

Os resultados obtidos evidenciaram a necessidade de implementar dois processos interconectados, o Projeto do Sistema de Produção e o Planejamento e Controle da Produção, este último baseado nas práticas básicas do Sistema Last Planner. Deve-se destacar que houve a necessidade de adaptar os modelos de PSP e do PCP existentes na literatura, ao contexto de sistemas pré-fabricados de aço. Por exemplo, a elaboração do PSP deve iniciar antes da etapa de detalhamento do projeto, possibilitando a realização de algumas alterações na sequência dos lotes de produção nos diferentes setores da empresa.

Destaca-se também que se criou uma instância de planejamento de controle integrado no nível de médio prazo, a ser desenvolvido por uma equipe multifuncional, visando a reduzir incertezas relacionadas aos processos à montante da montagem. No entanto, durante a execução da obra E restrições relacionadas com o cliente e com a entrega de materiais impediram que as atividades fossem realizadas conforme o sequenciamento e o ritmo planejados. O resultado insatisfatório da implementação indicou que, apesar do esforço inicial de elaboração do PSP, ainda havia muita variabilidade nos processos, fato este que evidenciou a necessidade de realizar melhorias nas diretrizes propostas para a realização do processo de PCP. Ao fim dos estudos, foi proposto um conjunto de diretrizes, sendo que estas foram categorizadas para obras com distintos graus de complexidade (tipo A, B e C).

O estudo também destacou algumas contribuições teóricas relacionadas à gestão de sistemas pré-fabricados do tipo ETO, destacando a necessidade de um sistema de planejamento e controle integrado e da utilização do conceito de produção puxada, como forma de conviver com a complexidade. Neste contexto, o planejamento e controle da produção deve ser padronizado e sistemático nos seus diferentes níveis, sendo que os planos devem ser visuais, de fácil compreensão por todos os envolvidos. Além disto, devem ser desenvolvidas abordagens mais eficazes para a padronização de processos de produção, que contribuam para a efetiva redução da variabilidade e sincronização dos processos.

Como principais limitações pode-se apontar que o estudo teve como foco o processo de planejamento e controle do processo de montagem, não sendo estudo em profundidade a implementação do planejamento e controle integrado, envolvendo diferentes setores. Além disto, as diretrizes propostas foram baseadas em estudos empíricos realizados em uma única empresa, podendo ter sido influenciadas pelas particularidades desta empresa, que produz apenas sistemas construtivos de aço.

Como sugestões para futuros estudos, podem ser destacadas as seguintes:

(a) desenvolver estudos empíricos que avaliem o impacto da implementação das diretrizes propostas, levando em conta o contexto de outras empresas e outros tipos de sistemas construtivos do tipo ETO;

(b) propor meios para quantificar financeiramente os ganhos obtidos com a utilização das diretrizes propostas; e

(c) investigar formas de melhorar o fluxo de informação e materiais entre o processo de montagem de sistemas pré-fabricados do tipo ETO e as unidades de projeto, fabricação e logística, visando a sincronizar diferentes processos.

\section{Referências}

AKEL, N. G. et al. Considerations for streamlining a vertically integrated company: a case study. In: ANNUAL CONFERENCE OF THE INTERNATIONAL GROUP FOR LEAN CONSTRUCTION, 9., Singapore, 2001. Proceedings [...] Singapore: IGLC, 2001.

BALLARD, G. et al. Production system design in construction. In: ANNUAL CONFERENCE OF THE INTERNATIONAL GROUP FOR LEAN CONSTRUCTION, 9., Singapore, 2001. Proceedings [...] Singapore: IGLC, 2001. 
BALLARD, G. Lookahead planning: the missing link in production control. In: ANNUAL CONFERENCE OF THE INTERNATIONAL GROUP FOR LEAN CONSTRUCTION, 5., Gold Coast, 1997. Proceedings [...] Gold Coast: Griffith University, 1997.

BALLARD, G. The Last Planner System of Production Control. Ph.D. Thesis. School of Civil Engineering. Faculty of Engineering, The University of Birmingham, Birmingham, 2000.

BALLARD, G.; HARPER, N.; ZABELLE, T. Learning to see work flow: an application of lean concepts to precast concrete fabrication. Engineering, Construction and Architectural Management, v. 10, n. 1, p. 614, 2003.

BALLARD, G.; HOWELL, G. Implementing lean construction: stabilizing work flow. In: ALARCÓN, L. (ed.). Lean construction. Rotterdam: A.A. Balkema, 1997.

BALLARD, G.; HOWELL, G. Shielding production: an essential step in production control. Journal of Construction Engineering and Management, v. 124, n 1, p. 11-17, jan./feb. 1998.

BATAGLIN, F. S. et al. BIM 4D aplicado à gestão logística: implementação na montagem de sistemas préfabricados de concreto engineer-to-order. Ambiente Construído, Porto Alegre, v. 18, n. 1, p. 173-192, jan./mar. 2018.

BATAGLIN, F. S. et al. Model for planning and controlling the delivery and assembly of engineer-to-order prefabricated building systems: exploring synergies between Lean and BIM. Canadian Journal of Civil Engineering, v. 46, p. 1, 2019.

BERNHOLD, L. Simulation of nonsteady construction processes. Journal of Construction Engineering and Management, v. 115, n. 2, p. 163-178, 1989.

BERTRAND, J. W. M.; MUNTSLAG, D. R. Production control in engineer-to-order firms. International Journal of Production Economics, v. 30/31, p. 3-22, jul. 1993.

BORTOLINI, R.; FORMOSO, C. T.; VIANA, D. D. Site logistics planning and control for engineer-toorder prefabricated building systems using BIM 4D modeling. Automation in Construction, v. 98, p. 248264, 2019.

BULHÕES, I. R. Diretrizes para implementação de fluxo contínuo na construção civil: uma abordagem baseada na Mentalidade Enxuta. Campinas, 2009. Tese (Doutorado em Engenharia Civil) - Faculdade de Engenharia Civil, Arquitetura e Urbanismo da Universidade Estadual de Campinas, Campinas, 2009.

BULHÕES, I. R.; PICCHI, F. A. Redução do tamanho do lote em projetos como estratégia de implementação do fluxo contínuo em sistemas pré-fabricados. Ambiente Construído, Porto Alegre, v. 13, p. 161-175, 2013

CODINHOTO, R. Diretrizes para o planejamento integrado dos processos de projeto e produção na construção civil. Porto Alegre, 2003. Dissertação (Mestrado em Engenharia Civil) - Programa de PósGraduação em Engenharia Civil, Universidade Federal do Rio Grande do Sul, Porto Alegre, 2003.

DAVE, B. et al. Suggestions to improve lean construction planning. In: ANNUAL CONFERENCE OF THE INTERNATIONAL GROUP FOR LEAN CONSTRUCTION, 23., Perth, 2015. Proceedings [...] Perth: IGLC, 2015.

DICK, B. You want to do an action research thesis? Interchange, v. 2, n. 6, 1992.

EDEN, C.; HUXHAM, C. Action research for management research. British Journal of Management, v. 7, p. 75-86, 1996.

FORMOSO, C.T. et al. Termo de referência para o processo de planejamento e controle da produção em empresas construtoras. São Paulo: SINDUSCON/SP, 1999.

HOPP, W. J.; SPEARMAN, M. L. Factory physics: foundations of manufacturing management. Boston: Irwin Mc Graw-Hill, 1996.

HOWELL, G. A.; BALLARD, H. G. Managing Uncertainty in the Piping Process. Construction Industry Institute, University of Texas, Austin, p 103, sep. 1996. Research Report 47-13

HOWELL, G. A.; LAUfER, A.; BALLARD, H.G. Uncertainty and Project Objectives. Project Appraisal, v. 8, n. 1, 1993. 
JÄRVINEN, P. Action research is similar to design science. Quality \& Quantity International Journal of Methodology, v. 41:37-54, Department of computer Sciences, University of Tampere, Finland, 2007.

KEMMER, S. L.; HEINECK, L. F. M.; ALVES, T. C. Using the line of balance for production system design. In: ANNUAL CONFERENCE OF THE INTERNATIONAL GROUP FOR LEAN CONSTRUCTION, 16., Manchester, 2008. Proceedings [...] Manchester: IGLC, 2008.

KOSKELA, L. Application of the new production philosophy to construction. Stanford: Stanford University, 1992. Technical Report, n. 72.

LAUFER, A. et al. The multiplicity concept in construction project planning. Construction Management and Economics, London, v. 1, p. 53-65, 1994.

LAUFER, A.; TUCKER, R. L. Is construction project planning really doing its job? A critical examination of focus, role and process. Construction Management and Economics, London, v.5, p. 243266, 1987

LEMNA, G.; BORCHERDING, J.; TUCKER, R. Productive foremen in industrial construction. Construction Management and Economics, v. 112, n. 2, p. 192-210, 1986.

LIKER, J. K.; MEIER, D. O modelo Toyota: manual de aplicação. Porto Alegre, Bookman, 2007.

LITTLE, D. et al. Integrated planning and scheduling in the engineer-to-order sector. International Journal of Computer Integrated Manufacturing, v. 13, p. 545-554, jan. 2000.

LUKKA, K. The constructive research approach. In: OJALA, L.; HILMOLA, O.-P. Case study research in logistics. Turku: Turku School of Economics and Business Administration, 2003.

RODRIGUES, A. A. O projeto do sistema de produção no contexto de obras complexas. Porto Alegre, 2006. Dissertação (Mestrado em Engenharia Civil) - Programa de Pós- Graduação em Engenharia Civil, Universidade Federal do Rio Grande do Sul, Porto Alegre, 2006.

SACKS, R.; AKINCI, B.; ERGEN, E. 3D Modeling and Real-Time Monitoring In Support of Lean Production of Engineered-To-Order Precast Concrete Buildings. Annual Conference of the International Group for Lean Construction 2003, 11., Virginia, 2003. Proceedings [...]Virginia: IGLC, 2003.

SAMANIEGO, C. A.; GRANJA, A.; PICCHI, F. Integración de la gestión de fabricación y montaje de elementos de concreto pre-fabricados in situ, utilizando conceptos de lean thinking. Revista Ingeniería de Construcción, Chile, v. 1, n. 21, abr. 2006.

SCHRAMM, F. K.; COSTA, D. B. ; FORMOSO, C. T. O projeto do sistema de produção na gestão de empreendimentos habitacionais de interesse social. Ambiente Construído, Porto Alegre, v. 6, n. 2, p. 59-74, abr./jun. 2006

SCHRAMM, F. K.; FORMOSO, C. T. Projeto de sistemas de produção na construção civil empregando simulação no apoio à tomada de decisão. Ambiente Construído, Porto Alegre, v. 15, n. 4, p. 165-182, out.dez. 2015.

SMALLEY, A. The starting point for lean manufacturing: achieving basic stability. Management Services, v. 49, n. 4, p. 8-12, Winter 2005.

SOARES, A. C. Diretrizes para a manutenção e o aperfeiçoamento do processo de planejamento e controle da produção em empresas construtoras. Porto Alegre, 2003. Dissertação (Mestrado em Engenharia Civil) - Programa de Pós-Graduação em Engenharia Civil, Universidade Federal do Rio Grande do Sul, Porto Alegre, 2003.

TOMMELEIN, I. Pull-driven scheduling for pipe-spool installation: simulation of a lean construction technique. Journal of Construction Engineering and Management, v. 124, n. 4, p. 279-288, jul./aug. 1998.

TOMMELEIN, I.; BALLARD, G. Lookahead planning: screening and pulling. In: SEMINÁRIO INTERNACIONAL SOBRE LEAN CONSTRUCTION, São Paulo, 1997. Anais [...] São Paulo: Instituto de Engenharia de São Paulo, 1997.

TOMMELEIN, I.; WEISSENBERGER, M. More just-in-time: location of buffers in structural steel supply and construction processes. In: ANNUAL CONFERENCE OF THE INTERNATIONAL GROUP FOR LEAN CONSTRUCTION, 7., Berkeley, 1999. Proceedings [...] Berkeley: IGLC, 1999. 
VAN AKEN, J. E. Management research based on the paradigm of the design sciences: the quest for fieldtested and grounded technological rules. Journal of Management Studies, v. 41, n. 2, p. 219-246, mar. 2004.

VIANA, D. D. Integrated production planning and control model for engineer-to-order prefabricated building systems. Porto Alegre, 2015. Tese (Doutorado em Engenharia Civil) - Programa de Pós-Graduação em Engenharia Civil, Universidade Federal do Rio Grande do Sul, Porto Alegre, 2015.

VIANA, D.; TOMMELEIN, I.; FORMOSO, C. Using modularity to reduce complexity of industrialized building systems for mass customization. Energies, v. 10, p. 1622, 2017.

YIN, R. K. Estudo de caso: planejamento e métodos. 2. ed. Porto Alegre: Bookman, 2002.

\section{Agradecimentos}

Os autores agradecem à Empresa, pela disponibilidade, participação e informações fornecidas; à CAPES e ao CNPq, pela bolsa de mestrado concedida.

\section{Fabiana Fabro}

Núcleo Orientado pela Inovação da Edificação | Universidade Federal do Rio Grande do Sul | Av. Osvaldo Aranha 99, sala 706 | Porto Alegre - RS - Brasil | CEP 90035-190 | Tel.: (51) 3308-3518 | E-mail: fabiana.engcivil@gmail.com

\section{lamara Rossi Bulhões}

Departamento Interdisciplinar | Universidade Federal do Rio Grande do Sul | Rodovia RS 030, 11.700 - km 92, Emboaba | Tramandaí - RS Brasil | CEP 95590-000 | Tel.: (51) 3308-1330 | E-mail: iamara.bulhoes@ufrgs.br

\section{Carlos Torres Formoso}

Núcleo Orientado pela Inovação da Edificação | Universidade Federal do Rio Grande do Sul | E-mail: formoso@ufrgs.br

\section{Marcus Costa Tenório Fireman}

Programa de Pós-Graduação em Engenharia Civil: Construção e Infra-Estrutura | Universidade Federal do Rio Grande do Sul | Av. Osvaldo Aranha 99, sala 706 | Porto Alegre - RS - Brasil | CEP 90035-190 | Tel.: (51) 3308-4848 | E-mail: marcusctf@gmail.com

\section{Ambiente Construído}

Revista da Associação Nacional de Tecnologia do Ambiente Construído Av. Osvaldo Aranha, 99 - 3o andar, Centro

Porto Alegre - RS - Brasil

$$
\text { CEP } 90035-190
$$

Telefone: +55 (51) 3308-4084

Fax: +55 (51) 3308-4054

www. seer. ufrgs. br/ ambienteconstruido

E-mail: ambienteconstruido@ufrgs.br 